\title{
A NUTRIGENÔMICA COMO MÉTODO DE PREVENÇÃO E TRATAMENTO DE DOENÇAS
}

Nutrigenomic as a method of prevention and treatment of diseases Desafios

La nutrigenomica como método de prevención y tratamiento de enfermedad

\section{Samantha Assakawa Ludgero da Silva Roque ${ }^{* 1}$, José Antônio Roque Ferreira Oliveira², Raphael Sanzio Pimenta ${ }^{1}$.}

${ }^{1}$ Laboratório de Microbiologia Geral e Aplicada, Curso de Mestrado em Ciência e Tecnologia de Alimentos, Universidade Federal do Tocantins, Palmas, Tocantins, Brasil.

${ }^{2}$ Curso de Engenharia Agronômica, Universidade Estadual do Tocantins - UNITINS, Palmas, Tocantins, Brasil

*Correspondência: Laboratório de Microbiologia Geral e Aplicada Universidade Federal do Tocantins, Av. NS 15, 109 Norte, Palmas, Tocantins, Brasil.CEP:77.010-090.e-mail: pimentars@uft.edu.br

\section{RESUMO}

A incidência de doenças nutricionais crônicas não transmissíveis vêm aumentando em todo o mundo, consequentemente a busca e o aperfeiçoamento de tratamentos e meios de prevenção também. Com a conclusão do projeto Genoma Humano em 2003 tem sido possível obter uma melhor compreensão sobre a expressão de genes no organismo humano. Como uma das ramificações desse acontecimento, surge então a área da nutrigenômica (ciência que tem estudado as interações entre a alimentação e os genes de um determinado indivíduo). Os alimentos possuem compostos que podem favorecer expressões gênicas no organismo de quem os consomem. Os costumes alimentares, a busca pela qualidade de vida, estresse, a exposição a substâncias poluentes e outros fatores revelam a necessidade de uma dieta individualizada. Com a nutrigenômica isso será possível, bem como também a redução de gastos (com internações, cirurgias, e tratamentos farmacológicos), prevenção e tratamento de doenças como Alzheimer, Síndrome de Down, diabetes mellitus tipo 2, fibromialgia entre outras.

Palavras-chave: genoma, expressão gênica, alimentação, prevenção de doenças.

\section{ABSTRACT}

The incidence of chronic non-communicable nutritional diseases is increasing worldwide, consequently the search and improvement of treatments and means of prevention as well. With the completion of the Human Genome project in 2003 it has been possible to gain a better understanding of the expression of genes in the human organism. As one of the ramifications of this event, then comes the area of nutrigenomics (science that has studied the interactions between food and the genes of a given individual). Foods contain compounds that may favor gene expression in the body of those who consume them. Eating habits, the quest for quality of life, stress, exposure to pollutants and other factors reveal the need for an individualized diet. With nutrigenomics this will be possible, as well as the reduction of expenses (with hospitalizations, surgeries, and pharmacological treatments), prevention and treatment of diseases such as Alzheimer's, Down Syndrome, type 2 diabetes mellitus, fibromyalgia among others.

Keywords: genome, gene expression, food, disease prevention.

\section{RESUMEN}

La incidencia de enfermedades viene aumentando en todo el mundo, consecuentemente la búsqueda y el perfeccionamiento de tratamientos y medios de prevención también. Con la tecnología y la conclusión del proyecto Genoma Humano en 2003 ha sido posible mejorar la comprensión sobre la expresión de genes en el organismo humano. Como una de las ramificaciones de ese acontecimiento, surge el área de la nutrigenómica, ciencia que estudia las interacciones entre la alimentación y los genes de un determinado individuo. Los alimentos poseen compuestos que pueden favorecer expresiones génicas en el organismo de quien los consume. Las costumbres alimenticias, la búsqueda de la calidad de vida, el ritmo acelerado, la exposición a sustancias contaminantes y otros 
factores revelan la necesidad de una dieta individualizada. Con la nutrigenómica esto será posible, así como también la reducción de gastos con internaciones, cirugías, y tratamientos farmacológicos, la prevención y el tratamiento de enfermedades como Alzheimer, Síndrome de Down, diabetes mellitus tipo 2, fibromialgia, entre otras.

Descriptores: Genoma, expresión génica, alimentación, prevención de enfermedades.

\section{INTRODUÇÃO}

No decorrer da vida, um indivíduo está exposto a diversos fatores que podem favorecer o surgimento de determinadas doenças. Entre eles temos a poluição, raios ultravioletas de maneira excessiva, tabagismo, alcoolismo, infecções, sedentarismo, o genoma do indivíduo (hereditariedade) e a má alimentação.

Segundo a Organização Mundial de Saúde (OMS), nos últimos 50 anos a mortalidade causada por doenças nutricionais crônicas não transmissíveis apresentaram um aumento significativo (OMS/WHO, 2014). E $\quad$ o sedentarismo, bem como uma alimentação inadequada (principalmente após o surgimento dos fast foods) tem favorecido esse acontecimento (Conti, 2010).

No período que compreende os anos 1930-1980, o perfil nutricional da sociedade brasileira era caracterizado pela prevalência de doenças carenciais. Entretanto, atualmente esse perfil foi sobreposto pelas doenças nutricionais crônicas não transmissíveis (DCNTs). As DCNTs afetam todo tipo de classe social, racial e temporal (Tessarin e Silva, 2013). E seus gastos para os serviços de saúde pública são consideráveis. Isso revela a necessidade de maior atenção para essa área (Conti, 2010; Vasconcelos, 2010).

Devido o contato diário (desde o útero da mãe), o alimento tem sido considerado um dos principais fatores de influência na modulação da expressão gênica e, consequentemente, o possível desenvolvimento de doenças. Com isso, vê-se necessário uma correta alimentação para a prevenção desses males que acometem pessoas no mundo todo atualmente (Sanhueza e Valenzuela, 2012; Vieira et al., 2015).

Diversos estudos têm observado a necessidade de uma alimentação mais correta e individualizada e com a conclusão do projeto Genoma Humano em 2003, esse desejo tem se tornado realidade. Após 2003, ramificações na área da biologia molecular tem surgido e tomado espaço em áreas não somente na medicina, mas também na nutrição. Esse movimento deu origem a nutrigenômica (Marti et al., 2005; Conti, 2010; Tessarin e Silva, 2013).

A nutrigenômica é a ciência que tem estudado as interações entre a alimentação e os genes de um determinado indivíduo. Através do estudo do genótipo é possível avaliar a presença de genes que favorecem o desenvolvimento de doenças específicas e assim estabelecer uma dieta personalizada. Nessa ciência, tanto o alimento pode influenciar a expressão dos genes, como também os genes podem indicar a necessidade de consumo de alguns nutrientes (Conti, 2010; Vieira et al., 2015).

Este artigo visou a realização de uma revisão bibliográfica atualizada sobre este novo ramo da ciência, a nutrigenômica.

\section{A influência dos alimentos na regulação gênica}

Os alimentos possuem substâncias, que quando ingeridas auxiliam na regulação da 
expressão gênica de um organismo. Assim sendo, a nutrigenômica busca analisar a interação dos nutrientes ingeridos e sua interação com o genoma humano, encontrando assim formas de ajudar na promoção da saúde e prevenção de doenças (Tessarin e Silva, 2013; Vieira et al., 2015).

Os nutrientes presentes nos alimentos podem induzir alterações nos padrões de metilação do DNA e na expressão genética. Por isso, dietas personalizadas podem ajudar a promover a saúde e reduzir o risco de DCNTs como doenças cardiovasculares, câncer, diabetes entre outras (Slomko et al., 2012; Vieira et al., 2015).

A reação química denominada metilação é a adição de um radical metil (CH3) em regiões promotoras de genes, podendo assim anular a expressão do mesmo. Essa ação só ocorre no organismo porque as enzimas DNA metiltransferases utilizam a S-adenosilmetionina (SAM) como doadora do radical metil. Entretanto, sabe-se que a disponibilidade da SAM é grandemente influenciada pela dieta alimentar (Milagro e Martínez, 2013; Vieira et al., 2015).

\section{A nutrigenômica e a prevenção de doenças Neoplasias}

Diversos estudos buscam avaliar a nutrigenômica como meio de prevenção e tratamento de neoplasias, os quais revelam ser um problema mundial. As neoplasias são caracterizadas pela proliferação anormal de células, de forma parcial ou totalmente descontrolada e é a segunda maior causa de mortes por doenças no Brasil. Estima-se que em
2030 haverá cerca de 21,4 milhões de casos novos de câncer (Tessarin e Silva, 2013; MS/INCA, 2014; Vieira et al., 2015).

Uma enzima conhecida atualmente e com grande atividade em neoplasias é a desacetilase de histona (HDAC), que inibe genes supressores tumorais e de reparo do DNA. Porém, substâncias encontradas em fibras solúveis (butirato), no alho, cebola (dialildissulfeto) e brócolis (sulforato) podem inibir sua atividade, favorecendo assim a saúde do indivíduo acometido pela doença (Ordovás, 2013; Tessarin e Silva, 2013; Vieira et al., 2015).

Outros acontecimentos importantes que devem ser levados em consideração quando falamos de nutrigenômica é a formação de radicais livres e o processo de oxidação. Radicais livres são átomos ou moléculas que contém elétrons não pareados, que possuem sua reatividade química aumentada e podem existir independentemente (Vieira et al.; 2015). Barbosa et al. (2010), afirma que sua formação se dá pelas mitocôndrias no processo de metabolismo do oxigênio no corpo e podem causar câncer, diabetes e aterosclerose. De forma semelhante, a oxidação no organismo pode causar consequências graves, revelando assim a importância dos antioxidantes (Vieira et al., 2015).

Estudos afirmam que antioxidantes (Tabela 1) podem retardar ou até mesmo prevenir o aparecimento do câncer. Além de serem facilmente encontrados em diversos alimentos (Leite e Sarni, 2003; Peluzio et al, 2010; Cominetti et al., 2011; Nasser et al., 2011; Vidal et al., 2012; Vieira et al., 2015). 
Tabela 1 - Relação antioxidante $\mathrm{x}$ alimento.

\begin{tabular}{|c|c|c|}
\hline Antioxidantes & $\begin{array}{l}\text { Alimentos } \\
\text { presentes }\end{array}$ & Referências \\
\hline selênio & $\begin{array}{l}\text { cereais integrais, } \\
\text { castanhas e } \\
\text { amêndoas. }\end{array}$ & $\begin{array}{c}\text { Cominett } e t \\
\text { al., } 2011\end{array}$ \\
\hline $\begin{array}{l}\text { alfa-tocoferol/ } \\
\text { vitamina } \mathrm{E}\end{array}$ & $\begin{array}{l}\text { gérmen de trigo, } \\
\text { avelã, óleos poli- } \\
\text { insaturados } \\
\text { extraídos de } \\
\text { vegetais como } \\
\text { algodão, milho e } \\
\text { soja. }\end{array}$ & $\begin{array}{c}\text { Leite e Sarni, } \\
2003 \text {; } \\
\text { Vieira } \text { et al., } \\
2015\end{array}$ \\
\hline
\end{tabular}

\begin{tabular}{ccc}
\hline $\begin{array}{c}\text { ácido } \\
\text { ascórbico/ } \\
\text { vitamina C }\end{array}$ & $\begin{array}{c}\text { acerola, laranja, } \\
\text { caju. }\end{array}$ & $\begin{array}{c}\text { Peluzio } \text { et al., } \\
2010\end{array}$ \\
\hline resveratrol e & & \\
quercitina & uva. & Vidal et al., \\
\hline antoxantina & batata, morango, & Vidal et al., \\
& cebola, uva e & $2012 ;$ \\
& laranja. & Vieira et al., \\
& & 2015 \\
\hline antocianina & açaí, uva, & Vidal et al., \\
& jabuticaba e & $2012 ;$ \\
& amora. & Vieira et al., \\
& & 2015 \\
\hline fitoestrógenos & soja, ervilha e & Vidal et al., \\
& amendoim. & 2012 \\
\hline flavonoides & frutas cítricas, & Nasser et al., \\
& tomate e & $2011 ;$ \\
& pimentão. & Vidal et al., \\
& & 2012 \\
\hline taninos & soja, laranja, & Vidal et al., \\
& mamão, pêssego e & 2012 \\
& milho. & \\
\hline licopeno & tomate, goiaba, & Vidal et al., \\
& melancia e & $2012 ;$ \\
& beterraba. & Vieira et al., \\
& & 2015 \\
\hline & &
\end{tabular}

Fibromialgia e doenças circulatórias

A fibromialgia é uma síndrome frequente em pessoas de meia idade (mas pode afetar adolescentes, crianças e idosos) e apresenta sintomas como dor crônica, fadiga, alterações no sono, ansiedade e depressão. Embora não existam recomendações alimentares específicas, sabe-se que os portadores de tal síndrome podem beneficiar-se com uma dieta rica em antioxidantes (Siena e Marrone, 2009; Silva, 2011; Mazocco e Chagas, 2015; Silva e Schieferdecker, 2017).

Alguns nutrientes, ingeridos como suplementos também vêm apresentando muitos benefícios à saúde. Alguns exemplos são os ácidos graxos essenciais (importantes para manter a integridade da membrana celular e ajudar na síntese de prostaglandinas), substâncias provenientes de peixes de água fria (principalmente ômega-3, são capazes de alterar a expressão gênica de mais de 100 genes. Inibindo assim o desenvolvimento da aterosclerose, auxiliando no fluxo sanguíneo e na transmissão dos impulsos nervosos), o resveratrol (capaz de reprimir a expressão de genes com capacidade vasodilatadoras e vasoconstritoras, beneficiando àqueles com doenças cardiovasculares), e o procianidólico oligômero (capaz de proteger músculos e prevenir artrite e bursite) (Giraldi, 2010; Vieira et al., 2015; Silva e Schieferdecker, 2017).

\section{Alzheimer}

Nos casos de Alzheimer, os polifenóis antioxidantes têm obtido resultados que demonstraram ser uma boa alternativa para retardar a progressão da doença (Silva, 2011). Um exemplo é a romã, que é capaz de reduzir o dano oxidativo, inibir citocinas, melhorar a memória, função motora e reduzir a ansiedade. A epigalocatequina-3-galato (EGCG) presente no chá verde reduz a atividade da enzima DYRK1A. O aumento dessa enzima está associado ao maior risco de Alzheimer (Zimmermann e Kirsten, 2008; Torres, 2016).

Atualmente, sabe-se que indivíduos com Síndrome de Down apresentam maior 
dificuldade de realizarem a metilação, característica essa que contribui para o envelhecimento acelerado e surgimento de doenças de maneira precoce (Smith, 1999). Pacientes com tal síndrome também possuem maior risco de desenvolverem Alzheimer, principalmente pelo fato de que o estresse oxidativo (característico da Síndrome de Down) também eleva a excitação glutamatérgica, contribuindo assim para o surgimento de seus sintomas (Torres, 2016; Vasconcelos, 2019).

\section{Diabetes}

Outra aplicabilidade do uso da nutrigenômica bem demonstrada ser refere ao combate do diabetes mellitus tipo 2. Que consiste em uma doença metabólica muito frequente no mundo todo atualmente $(90 \%$ dos casos de diabetes) caracteriza-se pela hiperglicemia como consequência da sensibilidade diminuída à insulina no organismo do portador. Apesar de sua maior prevalência na terceira idade, sabe-se que a incidência em jovens vem crescendo a cada ano (Palou et al., 2004; López e Casaverde, 2016; Moraes et al., 2017).

Nesse tipo de diabetes as células não conseguem metabolizar a glicose de maneira eficiente, podendo assim causar visão embaçada, dificuldade na cicatrização de feridas, o chamado 'pé de diabético' e outras complicações (López e Casaverde, 2016; Moraes et al., 2017; Fonseca e Rached, 2019).

Por ser uma doença diretamente relacionada à nutrição/alimentação, o estudo de sua relação gene-nutriente se torna imprescindível (Palou et al., 2004). Um estudo realizado em 2012 observou que a ingestão de ácido fólico por pacientes diabéticos do tipo 2 reduziu em parte sua resistência à insulina (Torres, 2016; Pereira 2019).

\section{Controle da lipidemia}

Apesar da grande semelhança genética entre os humanos $(99,9 \%)$ as diferenças de $0,1 \%$ são responsáveis por muitas alterações como cor da pele, olhos, cabelos, necessidades de determinados nutrientes, compostos bioativos e também do maior ou menor risco de desenvolvimento de doenças. Essas diferenças são denominadas polimorfismos de nucleotídeos únicos (SNPs) (Conti, 2010; Tessarin e Silva, 2013; Vieira et al., 2015).

Um SNP de grande importância foi identificado no gene PPAR $\gamma$, que controla em parte as concentrações sanguíneas de triacilglicerol (Conti, 2010). Pessoas com esse tipo de polimorfismo apresentam maiores concentrações dessa substância e portanto, devem reduzir o consumo de alimentos gordurosos para evitarem problemas cardíacos no futuro (Conti, 2010; Day e Loss, 2011; Youngson e Morris, 2013; Huang e Hu, 2015).

Outro SNP de interesse foi observado no gene APOA1. Indivíduos com esse polimorfismo não são beneficiados com o ômega-3, quando este beneficiaria outros, aumentando as concentrações do colesterol HDL (Conti, 2010; Giraldi, 1010).

\section{CONCLUSÃO}

O conhecimento relacionado à nutrigenômica se mostra de grande importância para a sociedade, a fim de melhorar a qualidade de vida da população. Apesar de ser uma ciência recente que necessita mais estudos, sua aplicação 
prática será ainda mais imprescindível em um futuro próximo.

Modificando a dieta e costumes alimentares é possível reduzir consideravelmente os gastos utilizados com tratamentos/terapias farmacológicas de pacientes. A nutrigenômica tem se destacado também por essa capacidade de prevenção e redução de custos relacionados aos serviços de saúde.

A possibilidade de cada indivíduo ter acesso ao seu próprio sequenciamento genético seria benéfica em diversas formas. Permitindo os nutricionistas e médicos prescreverem alimentos e remédios que mais corretamente se adequam ao organismo do indivíduo, favorecendo uma vida mais prolongada e melhor vivida da infância à velhice. O estudo adequado, principalmente de pacientes oncológicos é difícil devido às diversas variáveis existentes, mas não existem dúvidas de que a ingestão de alimentos adequados beneficiam os pacientes em todas as etapas do tratamento. Contudo, os custos do sequenciamento genômico total ainda são muito elevados o que pode dificultar o acesso dos profissionais de saúde a esta informação. Apesar disto, tem se observado uma redução significativa nos valores relacionados ao sequenciamento de DNA, e provavelmente em breve estes dados devem estar mais acessíveis para a sociedade de forma geral.

Esse estudo possibilitou novas reflexões sobre o tema, bem como destacou a importância desse conhecimento. Sábio ensinamento do pai da medicina ocidental Hipócrates, quando disse que as pessoas deveriam deixar seus alimentos serem seus remédios. Essa frase levou ao surgimento de muitas descobertas que temos hoje. E a nutrigenômica visa buscar mostrar na prática que isso realmente é possível e verdadeiro.

Todos os autores declararam não haver qualquer potencial conflito de interesses referente a este artigo.

\section{REFERÊNCIAS}

BARBOSA, K.B.F.; COSTA, N.M.B.; ALFENAS, R.C.G.; DE PAULA, S.O.; MINIM, V.P.R.; BRESSAN, J. Estresse oxidativo: conceito, implicações e fatores modulatórios. Revista de Nutrição, Campinas, v. 23, n. 4, p. 630-643, 2010

COMINETTI, C.; BORTOLI, M.C.; ABDALLA, D.S.P.; COZZOLINO, S.M.F. Considerações sobre estresse oxidativo, selênio e nutrigenética. Revista Nutrire: Sociedade Brasileira de Alimentação e Nutrição, São Paulo, SP, v. 36, n. 3, p. 131-153, 2011.

CONTI, A. Nutrigenômica: a ciência da nutrição na era pós genoma. Food Ingredients Brasil, n.15, 2010. Disponível em:<http://revi stafi.com.br/upload_arquivos/201606/20160 60914388001465320775.pdf >. Acessado em 10 jan 2018.

DAY, F.R., LOOS, R.J. Developments in obesity genetics in the era of genome-wide association studies. Journal of Nutrigenetics and Nutrigenomics. v.4, n.4, p.222-38, 2011.

Descritores em Ciências da Saúde: DeCS. 2019. Ed. rev. ampl. e atual. São Paulo: BIREME / OPAS / OMS, 2017. Disponível em: <http://d ecs.bvsalud.org>. Acesso em 22 de jul. 2019.

FONSECA, K.P.; RACHED, C.D.A. Complicações do diabetes mellitus. International Journal of Health Management, ed.1, 2019. Disponível em: <http://www.ijhmreview.org/ijhmreview/article /view/149/88>. Acessado em junho 2019.

GIRALDI, A. A dieta do DNA. Unespciência, Unesp, p.42-43, 2010. Disponível em: 
<https://www.unesp.br/aci/revista/ed15/quemdiria>. Acessado em 10 jan 2018.

HUANG, T., HU, F.B. Gene-environment interactions and obesity: recent developments and future directions. BMC Medical Genomics, v.8, n.1, p.S2, 2015.

LEITE, H.P.; SARNI, R.S. Radicais livres, antioxidantes e nutrição. Revista Brasileira de Nutrição Clínica, São Paulo, v. 18, n. 2, p. 8794, 2003.

LÓPEZ, Y.H.G.; CASAVERDE, V.C. Factores asociados al sobrepeso y obesidad en niños. Trabajo académico para título en Especialista por la Universidad Privada Norbert Wiener. Lima-Peru, 2016.

MARTI, A.; MORENO-ALIAGA, M.J.; ZULET, M.A.; MARTÍNEZ, J.A. Avances en nutrición molecular: nutrigenómica y/o nutrigenética. Nutrición Hospitalaria, NavarraEspanha, vol. XX, n.3, p.157-164, 2005.

MAZOCCO, L.; CHAGAS, P. Terapia nutricional na reabilitação de doenças crônicas osteoarticulares em idosos. Revista Brasileira de Ciências do Envelhecimento Humano, v.12, n.3, p.309-317, 2015.

MILAGRO, F.I.; MARTÍNEZ, J.A. Epigenética en obesidad y diabetes tipo 2: papel de la nutrición, limitaciones y futuras aplicaciones. Revista Chilena de Endocrinología y Diabetes, v.6, n.3, p.108-114, 2013.

MINISTÉRIO DA SAÚDE. Instituto Nacional de Câncer - INCA. Estimativa 2014: Incidência de câncer no Brasil, Rio de Janeiro - RJ, p.124, 2014.

MORAES, R.C.S.; ASSIS, C.S.; DINIZ, T.G. Diabetes tipo 2: suas alterações genéticas e o uso da dieta do mediterrâneo como forma terapêutica no tratamento da doença - uma revisão. Congresso Brasileiro de Ciências da Saúde (CONBRACIS), Universidade Federal da Paraíba, Paraíba-PB, 2017.

NASSER, et al. Avaliação do estresse oxidativo no sangue de consumidores habituais de suco de laranja. Revista de Ciências Farmacêuticas Básica e Aplicada, Araraquara,v. 32, n. 2, p. 275-279, 2011.
ORDOVÁS MUÑOZ, J.M. Predictors of obesity: the "power" of the omics. Nutrición Hospitalaria, v.28, n.5, p.63-71, 2013.

Organização Mundial de Saúde. Global status report: on noncommunicable diseases. [S.1.] OMS/WHO, 2014. Disponível em: <http:// apps.who.int/iris/bitstream/10665/148114/1/978 9241564854_eng.pdf?ua=1>. Acessado em 10 jan 2018.

PALOU, A.; BONET, M.L.; PICÓ, C.; RODRIGUEZ, A.M. Artículos de revisión: Nutrigenómica y obesidad. Revista de Medicina de la Universidad de Navarra, [Navarra-Espanha], v.48, n.2, p.36-48, 2004

PELUZIO, M.C.G; ROSA, D.D.; OLIVEIRA, V. P. Vitaminas Antioxidantes. In: COSTA, N. M. B.; ROSA, C. O. B. Alimentos Funcionais: componentes bioativos e efeitos fisiológicos. Rubio, v.1, p. 37-57, 2010.

PEREIRA, J.R.R. Efeito da ingestão de sucos de laranja, variedades Moro e Pera, sobre o estresse oxidativo de camundongos saudáveis e com resistência à insulina induzida por dieta hiperlipídica e hiperglicídica. Dissertação para título de Mestrado da Universidade de São Paulo - USP, 2019.

SANHUEZA, C.J.; VALENZUELA, B.A. Artículos de actualización: Nutrigenómica: revelando los aspectos moleculares de una nutrición personalizada. Revista Chilena de Nutrición, [Santiago-Chile], v.39, n.1, mar 2012.

SIENA, L.R.; MARRONE, L. A influência da alimentação na redução ou no agravamento dos sintomas apresentados em pacientes portadores de fibromialgia. Revista Terra e Cultura, n.48/49, ed. 25, p.13-19, 2009.

SILVA, A.F.; SCHIEFERDECKER, M.E.M. Recomendações nutricionais para o tratamento da fibromialgia. DEMETRA: Alimentação, Nutrição \& Saúde, v.12, n.3, p.751-765, 2017.

SILVA, S.M.L. Hábito alimentar e saúde. Brazilian Journal of Health, v.2, n.2/3, p.138142, 2011. 
SLOMKO, H.; HEO, H.J.; EINSTEIN, F.H.

Epigenetics of obesity and diabetes in humans.

Endocrinology, v.153, n.3, p.1025-1030, 2012.

SMITH, M.A.C. Doença de Alzheimer. Revista Brasileira de Psiquiatria, v.21, 1999. Disponível em: <http://www.scielo.br/pdf/rbp/ v21s2/v21s2a03.pdf $>$. Acesso em jun 2019.

TESSARIN, M.C.F.; SILVA, M.A.M. Nutrigenômica e câncer: uma revisão.Cadernos UniFOA, edição especial, p.79-96, mai 2013.

TORRES, A.A.L. Aspectos nutricionais associados ao envelhecimento de indivíduos com síndrome de Down: uma revisão integrativa. Revista Brasileira de Ciências do Envelhecimento Humano (RBCEH), Passo Fundo-RS, v.13, n.3, p.367-387, set/dez 2016.

VASCONCELOS, F.A.G. A ciência da nutrição em trânsito: da nutrição e dietética à nutrigenômica. Revista de Nutrição, CampinasSP, ed.23, n.6, p.935-945, nov/dez 2010.

VASCONCELOS, M.H.M. Estudo da ocorrência de biomarcadores da instabilidade do genoma na mucosa oral em crianças com síndrome de Down. Trabalho para título de Bacharel da Universidade Federal do Rio
Grande do Norte - UFRN, 2019. Disponível em: <https://monografias.ufrn.br/jspui/bitstr eam/123456789/8737/1/2014088284.pdf>. Acesso em jun 2019.

VIDAL, A.M.; DIAS, D.O.; MARTINS, E.S.M.; OLIVEIRA, R.S.; NASCIMENTO, R.M.S.; CORREIRA, M.G.S. A ingestão de alimentos funcionais e sua contribuição para a diminuição da incidência de doenças. Cadernos de Graduação - Ciências biológicas e da Saúde, Aracaju, v.1, n. 15, p. 43-52, 2012.

VIEIRA, J.A.T.; MARCHIORI, J.M.G.; MOREIRA, W.M.Q.M. A nutrigenômica na prevenção e combate às células neoplásicas. Revista Fafibe On-line, Bebedouro, São PauloSP, ed.8, n.1, p.140-153, 2015.

YOUNGSON, N.A., MORRIS, M.J. What obesity research tells us about epigenetic mechanisms. Philosophical Transactions of the Royal Society B: Biological Sciences, v.368, n.1609 p.20110337, 2013.

ZIMMERMANN, A.M.; KIRSTEN, V.R. Alimentos com função antioxidante em doenças crônicas: uma abordagem clínica. Disciplinarum Scientia, v.9, n.1, p.51-68, 2008. 